\title{
Acute Development of Ileus after Open Hysterectomy: A Case Report
}

\author{
Young Joon Kim, Ho Seok Lee, Sung Mi Hwang*
}

Department of Anesthesiology and Pain Medicine, Hallym University School of Medicine, Chuncheon Sacred Heart Hospital, Chuncheon, 24253, South Korea

DOI: $10.36347 /$ sjmcr.2020.v08i05.014

| Received: 08.05.2020 | Accepted: 15.05.2020 | Published: 19.05.2020

*Corresponding author: Dr. Sung Mi Hwang

Abstract

A 51-year-old woman underwent open subtotal hysterectomy and bilateral salpingo-oophorectomy under general anesthesia. General anesthesia was maintained with desflurane-oxygen-air and continuous infusion of remifentanil. The operation proceeded without problems. The duration of anesthesia was 2 hours 30 minutes. In the postanesthesia care unit, pethidine $(25 \mathrm{mg})$ was injected and the patient did not complain of nausea or vomiting. She remained in the postanesthesia care unit for approximately 40 minutes and was then transferred to a general ward. Three hours later, she complained of nausea and the nausea persisted and abdominal distention developed. After approximately 1 hour, dyspnea developed and her respiration rate reached 30/min. Abdominal radiography revealed diffuse small bowel ileus. An L-tube was inserted and dyspnea resolved within 30 minutes. After 1 hour 30 minutes, gas was expelled and recovery of abdominal distension was observed.

Keywords: Anesthesia, Ileus, Open hysterectomy.

Copyright @ 2020: This is an open-access article distributed under the terms of the Creative Commons Attribution license which permits unrestricted use, distribution, and reproduction in any medium for non-commercial use (NonCommercial, or CC-BY-NC) provided the original author and source are credited.

\section{INTRODUCTION}

Postoperative ileus is currently the most common cause of delayed discharge after abdominal surgery and must be distinguished from mechanical intestinal obstruction [1]. Although there are a number of definitions, conventional early postoperative small bowel obstruction is defined as obstruction that develops within 30 days of surgery [2-4]. It occurs more commonly in patients undergoing open abdominal surgery than in those undergoing laparoscopic surgery $[4,5]$.

Here, we describe a patient in whom small bowel distension developed immediately after open abdominal hysterectomy; the patient recovered immediately after Levin tube insertion. We perform a literature review and a discussion of the possible cause from an anesthesiologic perspective, as it occurred very quickly after surgery.

\section{Case Report}

A 51-year-old woman was diagnosed with myoma uteri and ovarian cyst approximately 11 months prior to presentation for surgery. She had no specific relevant medical history. She underwent open subtotal hysterectomy and bilateral salpingo-oophorectomy under general anesthesia. General anesthesia was maintained with desflurane-oxygen-air and continuous infusion of remifentanil. The operation proceeded without problems. The duration of anesthesia was 2 hours 30 minutes. Before the end of surgery, ramosetron was injected at a dose of $0.3 \mathrm{mg}$ and intravenous patient-controlled analgesia (PCA) was initiated, consisting of fentanyl $(1000 \mu \mathrm{g})$, ramosetron $(0.6 \mathrm{mg})$, nefopam $(80 \mathrm{mg})$, and normal saline in a total volume of $100 \mathrm{~mL}$ (basal rate, $2 \mathrm{~mL} / \mathrm{h}$; lockout interval, $15 \mathrm{~min}$; bolus dose, $2 \mathrm{~mL}$ ). In the postanesthesia care unit, pethidine $(25 \mathrm{mg})$ was injected and the patient did not complain of nausea or vomiting. She remained in the postanesthesia care unit for approximately 40 minutes and was then transferred to a general ward.

Three hours later, the patient complained of nausea and PCA was discontinued. However, the nausea persisted and abdominal distention developed. The patient then had a respiratory rate of $20 / \mathrm{min}$ and $\mathrm{SpO}_{2}$ of $99 \%$. However, after approximately 1 hour, dyspnea developed and the patient's respiration rate reached 30/min. Abdominal radiography revealed diffuse small bowel ileus (Fig-1). An L-tube was inserted and dyspnea resolved within 30 minutes (Fig2). After 1 hour 30 minutes, gas was expelled and recovery of abdominal distension was observed. The Ltube was removed and the patient was discharged without sequelae 2 days later. Review of her medical 
records revealed a slight ileus in the small bowel on abdominal computed tomography upon diagnosis of myoma uteri.

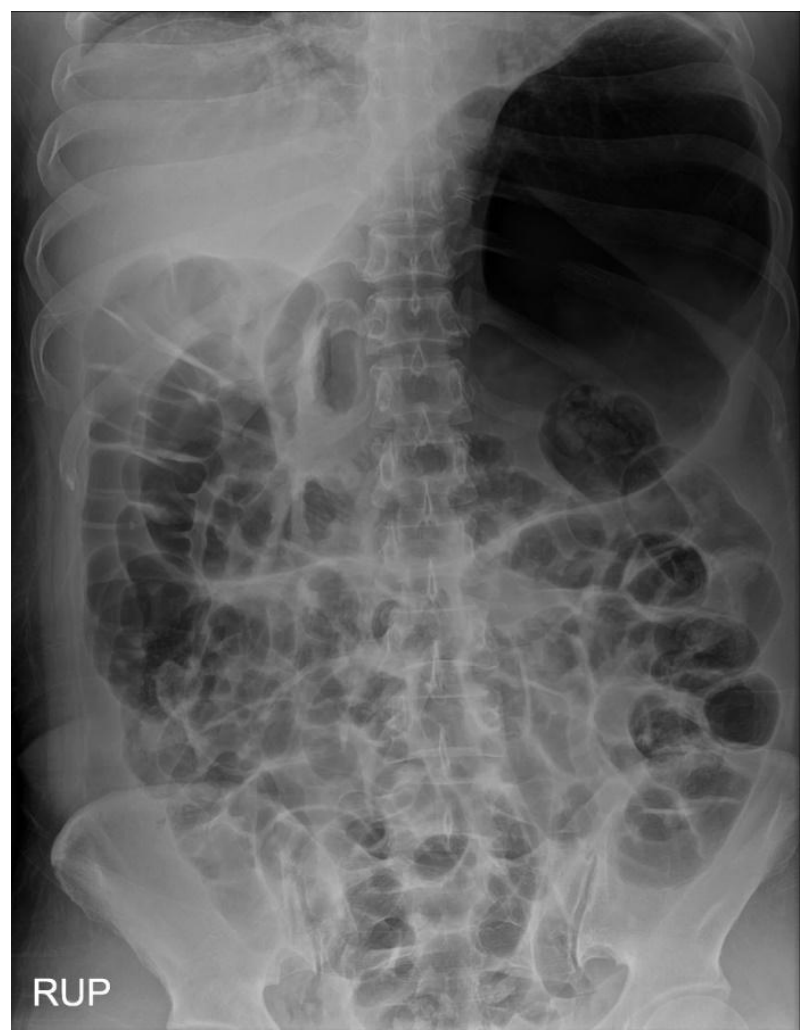

Fig-1: Abdominal radiograph shows diffuse small bowel ileus

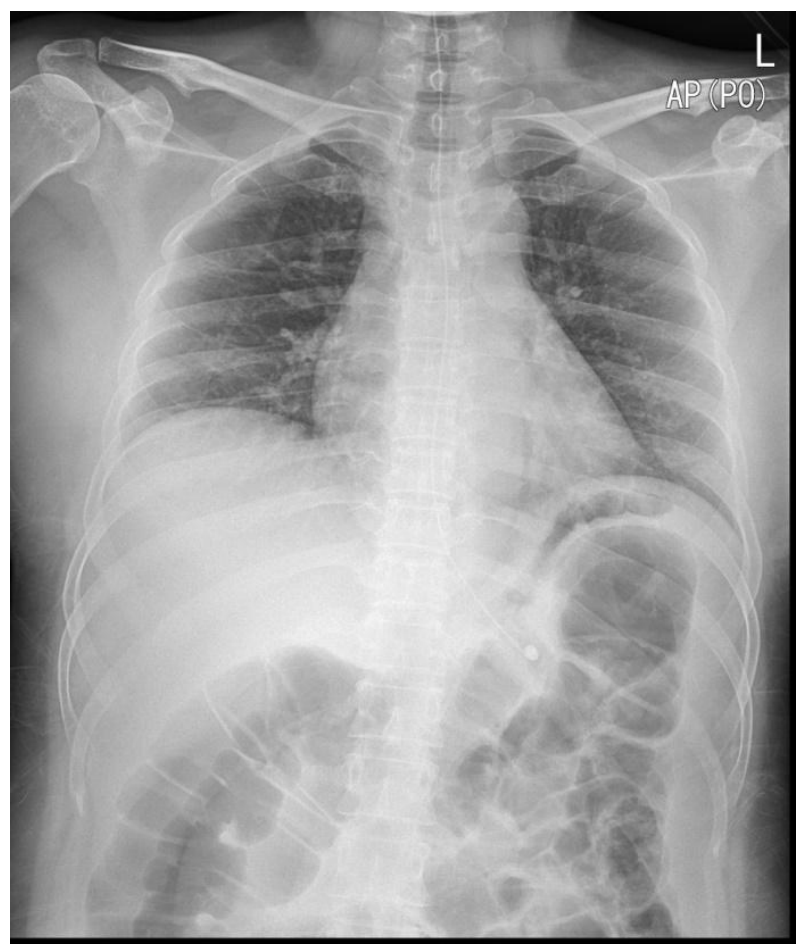

Fig-2: Abdominal radiograph shows decreased bowel distension after Levin tube insertion

\section{DISCUSSION}

Postoperative ileus is an abnormal pattern of bowel motility from the time of surgery, which is accompanied by various clinical symptoms (e.g., nausea, vomiting, abdominal distension, and delayed passage of flatus and stool) $[6,7]$. Because there is no internationally accepted standardized clinical definition of postoperative ileus and its mechanisms of development are multifactorial, the incidence and preoperative risk factors are unclear. However, postoperative ileus can be specifically defined as at least two episodes of emesis of at least $100 \mathrm{~mL}$ with abdominal distension and absence of bowel sounds [7]. Sugawara et al., [8] reported that colorectal surgery, open abdominal surgery, and smoking history are risk factors in patients undergoing major abdominal surgery. The incidence of clinically severe postoperative ileus after laparotomy for gynecological surgery has been reported to reach $14 \%$ [9].

Our patient had a risk factor of open hysterectomy and exhibited rapid ileus development after surgery. However, abdominal computed tomography performed for diagnosis of myoma uteri revealed mild ileus in the small intestine. Therefore, this patient may have been prone to onset of ileus.

Risk factors related to anesthesia include nitrous oxide and opioid use. Use of nitrous oxide during anesthesia in adults increases the risks of postoperative nausea and vomiting by activating the chemoreceptor trigger zone and the vomiting center in the medulla. Nitrous oxide may be hazardous in patients with acute intestinal obstruction and bowel distension because it tends to diffuse into gas-containing cavities [10]. Opioids injected during the perioperative period may play a central role in development of postoperative ileus, presumably through $\mu$-receptor-mediated reduction of transit [11]. Our patient had received alfentanil and remifentanil during anesthesia, with fentanyl-based postoperative PCA. The PCA was discontinued when the patient complained of nausea. The $\mu$-receptor antagonist, alvimopan, has been shown to effectively prevent postoperative ileus after abdominal hysterectomy; however, it is costly [12]. Prevention of postoperative ileus contributes to enhanced recovery after surgery; multiple studies have evaluated the risk factors, as well as potential therapeutic and preventive mechanisms (e.g., gum chewing, early enteral nutrition, and laparoscopic surgery) $[13,14]$.

\section{Conclusion}

Postoperative ileus is a common cause of delayed discharge after abdominal surgery. Therefore, better prophylaxis, prompt detection, and customized recovery management are needed after surgeries in patients with risk factors. 


\section{REFERENCES}

1. Postoperative ileus management council. Postoperative ileus: profiles, risk factors and definitions. Clinical consensus update in general surgery. 2006. http://www.clinicalwebcasts.com/pdfs/GenSurg_ WEB.pdf.

2. Carlson GL, Dark P. Acute intestinal failure. Curr Opin Crit Care. 2010 Aug;16(4):347-52.

3. Ong AW, Myers SR. Early postoperative small bowel obstruction: A review. Am J Surg. 2020 Mar; 219(3): 535-9.

4. Sajja SB, Schein M. Early postoperative small bowel obstruction. Br J surgery, 2004; 91: 683-91.

5. Duron JJ, Hay JM, Msika S, Gaschard D, Domergue J, Gainant A, Fingerhut A. Prevalence and mechanisms of small intestinal obstruction following laparoscopic abdominal surgery: a retrospective multicenter study. French Association for Surgical Research. Arch Surg. 2000 Feb; 135(2): 208-12.

6. Vather R, Trivedi S, Bissett I. Defining postoperative ileus: results of a systemic review and global survey. J Gastrointest Sur, 2013; 17: 962-72.

7. Steed HL, Capstick V, Flood C, Schepansky A, Schulz J, Mayes DC. A randomized controlled trial of early versus "traditional" postoperative oral intake after major abdominal gynecologic surgery. Am J Obstet Gynecol, 2002; 186(5): 861-5.

8. Sugawara K, Kawaguchi Y, Nomura Y, Suka Y, Kawasaki K, Uemura Y, Koike D, Nagai M, Furuya T, Tanaka N. Perioperative Factors Predicting Prolonged Postoperative Ileus After
Major Abdominal Surgery. J Gastrointest Surg. 2018 Mar; 22(3): 508-15.

9. Charoenkwan K, Phillipson G, Vutyavanich T. Early versus delayed (traditional) oral fluids and food for reducing complications after major abdominal gynaecologic surgery. Cochrane Database Syst Rev, 2007;4:CD004508.

10. Butterworth JF, Mackey DC, Wasnick JD. Inhalation anesthetics. In: Morgan \& Mikhail's Clinical Anesthesiology. 6th ed. Edited by Butterworth JF, Mackey DC, Wasnick JD: New York, McGraw-Hill. 2018, 159-63.

11. Pappagallo M. Incidence, prevalence and management of opioid bowel dysfunction. Am J Surg, 2001; 182:11S-18S.

12. Herzog TJ, Coleman RL, Guerrieri Jr JP, Gabriel K, Du W, Techner L, Fort JG, Wallin B. A doubleblind, randomized, placebo-controlled phase III study of the safety of alvimopan in patients who undergo simple total abdominal hysterectomy. American journal of obstetrics and gynecology. 2006 Aug 1;195(2):445-53.

13. Jernigan AM, Chen CCG, Sewell C. A randomized trial of chewing gum to prevent postoperative ileus after laparotomy for benign gynecologic surgery. International journal of gynecology and obstetrics, 2014; 127: 279-82.

14. An J, Noh H, Kim E, Lee J, Woo K, Kim H. Neuromuscular blockade reversal with sugammadex versus pyridostigmine glycopyrrolate in laparoscopic cholecystectomy: a randomized trial of effects on postoperative gastrointestinal motility. Korean J Anesthesiol, 2020;73(2): 137 44. 